\title{
Smart sport equipment: reshaping the sports landscape
}

\author{
Tiago M. Barbosa ${ }^{1^{*}}$
}

EDITORIAL

We are witnesses of "Industry $4.0^{\text {", the }} 4^{\text {th }}$ industrial revolution. In just a few years, we became a highly analytical society where at any given time massive datasets are produced, collected and analysed. Cities and countries have the vision of becoming smart societies, optimising the performance and wellbeing of their citizens. One can easily track and log all daily activities. The biggest challenge, though, is the management of an overwhelming amount of data.

Sports industry is no different. Sports is a reflection of the society. Athletes (of any level, from recreational all the way up to world-ranked), patients and practitioners (Physical Education teachers, coaches, analysts, physicians, therapists, etc.) are keen to track-down analytical parameters as well. Innovation and technology can help preventing and minimising sports injuries, enhancing sports technique or aid assessing the performance delivered.

The industry of smart sport equipment is growing up at a very fast pace. The number of wearable devices worldwide is expected to increase from 325 million in 2016 to over 830 million in 2020. The smart wearables for sports and fitness generated US $\$ 3.5$ billion in 2014 (Market Wired, 2016). The forecast is that smart garments sector will worth about US $\$ 34$ billion by 2020 (Lamkin, 2016). The smart textiles and smart fabrics market is expected to reach US $\$ 9.3$ billion by 2024 (Grand View Research, 2015).

These products can cater a wide range of consumers. The ones who are looking forward to more or less fashionable sportswear, sports accessories, information technology \& electronics consumers, etc. The common denominator among these consumers is being innovation- driven. There are commercially available smart wearables (or gear) to be used in all main sports, including aquatics, athletics, boating, cycling, gymnastics, invasion games, net sports, winter sports, and much more. Sports equipment and clothing can be instrumented with sensors, providing real-time analytical details on the subject's behaviour and performance. Data can be logged and analysed later on. Alternatively, it can be transmitted real-time to portable terminals (smartphones, tablets, smartwatches or laptops) and displayed immediately.

With this outlook as backdrop, there is an opportunity for sports sciences to play a key-role in the reshape of the sports landscape. Sports researchers can help on the design and validation of smart sport equipment, and be involved as endusers of these products. As end-users, sport researchers will not be spending so much time collecting and handling data. Rather, the job scope will shift more into analysis, interpretation and application of the findings. This will enable to provide swift real-time feedback to patients, athletes, coaches and others stakeholders in the sports fraternity. Data can be uploaded to a cloud and be available everywhere at any given time from any device. The design, and validation of new cutting-edge devices, of innovative solutions, are a great opportunity to bridge academia with industry. To carry out these projects is paramount to have interdisciplinary research teams with a wide array of skills, different expertise and backgrounds. The project will not end by the publication of a series of research papers. This should be followed-up by obtaining a patent. Also, it can help highly-trained graduates to join the workforce and even to foster the setup of start-ups.

\footnotetext{
${ }^{1}$ Editor-in-Chief of the Journal Motricidade; Physical Education \& Sports Science Academic Group, National Institute of Education, Nanyang Technological University

*NIE5-03-31, 1 Nanyang Walk, Singapore; Email: editor.in.chief@revistamotricidade.com
} 


\section{2 | TM Barbosa}

Several universities, mostly in Asia and Europe (notably the United Kingdom), are now offering courses in "Sports Technology" to undergraduate students. Some tertiary institutions, are offering also undergraduate and postgraduate programmes in this field. The curricula of such programmes touch topics such as innovation, design, and sports engineering with a strong emphasis in sport sciences. Sports technology is an exciting, cutting-edge and reasonable new field. Moreover, it is possible to set a pathway between academia (research and teaching) and industry (services). Ultimately, it is deemed to provide an added economical return to society, which one should not disregard.

REFERENCES
Grand View Research (2015). Smart
Textiles/Fabrics Market Worth $\$ 9.3$ Billion By
2024. Retrieved 2018 August 13, from
https://www.grandviewresearch.com
Lamkin, P. (2016). Wearable Tech Market To Be Worth $\$ 34$ Billion By 2020. Retrieved 2018 August 13, from https://www.forbes.com Market Wired (2016). Smart Wearables for Sports and Fitness Market Worth $\$ 44.2$ Billion by 2021 : Radiant Insights, Inc. Retrieved 2018 August 13, from http://www.marketwired.com

All content of Journal Motricidade is licensed under Creative Commons, except when otherwise specified and in content retrieved from other bibliographic sources. 